Article

\title{
Activin A-Mediated Regulation of XT-I in Human Skin Fibroblasts
}

\author{
Thanh-Diep Ly, Ricarda Plümers, Bastian Fischer, Vanessa Schmidt, Doris Hendig, Joachim Kuhn, \\ Cornelius Knabbe and Isabel Faust *iD
}

Institut für Laboratoriums- und Transfusionsmedizin, Herz- und Diabeteszentrum NRW, Universitätsklinik der Ruhr-Universität Bochum, Georgstraße 11, 32545 Bad Oeynhausen, Germany

* Correspondence: ifaust@hdz-nrw.de; Tel.: (+49)-5731-97-1234

Received: 9 March 2020; Accepted: 13 April 2020; Published: 14 April 2020

\begin{abstract}
Fibrosis is a fundamental feature of systemic sclerosis (SSc) and is characterized by excessive accumulation of extracellular matrix components like proteoglycans (PG) or collagens in skin and internal organs. Serum analysis from SSc patients showed an increase in the enzyme activity of xylosyltransferase (XT), the initial enzyme in PG biosynthesis. There are two distinct XT isoforms-XT-I and XT-II-in humans, but until now only XT-I is associated with fibrotic remodelling for an unknown reason. The aim of this study was to identify new XT mediators and clarify the underlying mechanisms, in view of developing putative therapeutic anti-fibrotic interventions in the future. Therefore, we used different cytokines and growth factors, small molecule inhibitors as well as small interfering RNAs, and assessed the cellular XT activity and XYLT1 expression in primary human dermal fibroblasts by radiochemical activity assays and qRT-PCR. We identified a new function of activin $\mathrm{A}$ as a regulator of XYLT1 mRNA expression and XT activity. While the activin A-induced XT-I increase was found to be mediated by activin A receptor type 1B, MAPK and Smad pathways, the activin A treatment did not alter the XYLT2 expression. Furthermore, we observed a reciprocal regulation of XYLT1 and XYLT2 transcription after inhibition of the activin A pathway components. These results improve the understanding of the differential expression regulation of XYLT isoforms under pathological fibroproliferative conditions.
\end{abstract}

Keywords: activin A; fibrosis; MAPK; proteoglycan; Smad; systemic sclerosis; xylosyltransferase

\section{Introduction}

The skin is the largest organ in the human body and provides a protective barrier against microorganisms, injuries and water loss [1]. Approximately $70 \%$ of its dry weight is formed by the extracellular matrix (ECM) [2]. The synthesis, deposition and remodelling of the ECM is critical for the maintenance of tissue homoeostasis under physiological conditions. Despite being strongly regulated, disturbances of these processes can result in severe pathological diseases, such as hypertrophic scarring, scleroderma and fibrosis induced by surgery, radiotherapy or medication [3].

The hallmark of these fibroproliferative conditions is the activation and differentiation of fibroblasts into myofibroblasts due to physical or inflammatory insults. These cells secrete vast amounts of ECM proteins that accumulate in the tissue and impair proper organ function [4]. Furthermore, myofibroblasts are engaged in paracrine and autocrine interactions with their surrounding environment by secretion of growth factors and cytokines like activin A and transforming growth factor $\beta 1$ (TGF $\beta 1$ ), which are increased in many tissues during fibrosis [5-7].

Though activin A and TGF $\beta 1$ belong to the TGF $\beta$ superfamily and provide structural similarities, activin $A$ is secreted as an active protein, whereas TGF $\beta 1$ is secreted as an inactive precursor and requires activation [8,9]. Activin A plays a crucial role in wound healing and inflammation, therefore 
providing a critical link between the process of inflammation and fibrotic response in systemic sclerosis (SSc), the prototype of fibrotic skin diseases [10-12]. Activin A production is stimulated by several pro-fibrotic mediators, including TGF $\beta 1$, interleukins (IL), endothelin-I, angiotensin-II and thrombin $[6,13,14]$. To promote fibroblast differentiation into myofibroblasts, exogenous activin A signals through combined type I and type II transmembrane kinase receptors, known as activin A receptor type 1B (ACVR1B) or activin receptor-like kinase 4 (ALK4) and ACVR2A or ACVR2B, which are shared by other TGF $\beta$ ligands, such as myostatin, nodal and growth and differentiation factor 11 [12,15]. In all instances, ligand complex formation leads to phosphorylation and activation of intrinsic receptor kinase domains, which facilitate phosphorylation cascades. Similar to pro-fibrotic core mediator TGF $\beta 1$, activin A mediates cellular responses via transcription factors mothers against decapentaplegic homolog 2/3 (Smad2/3)-dependent and non-canonical, Smad-independent signalling pathways, which involve the phosphorylation of the mitogen-activated protein kinases (MAPK) p38 MAPK, extracellular signal-regulated kinase (ERK) or c-Jun N-terminal kinase (JNK) in a cell type and cytokine-specific manner [16-18]. The activation of both the canonical as well as non-canonical signalling pathway has been demonstrated to be involved in fibrogenic changes $[13,16,19]$.

Like TGF $\beta 1$, activin A has a high affinity for the ECM by binding to heparin-sulphated proteoglycans (PG), such as perlecan, which are highly up-regulated in many human fibrotic conditions, including SSc $[10,16,20]$. The biological roles of PGs are related to their negatively charged glycosaminoglycan (GAG) chains that were post-translationally attached to the PG core proteins [20]. The formation of these GAG chains is initiated by xylosylation of specific serine units on preformed PG core proteins by the rate-limiting enzymes xylosyltransferase-I (XT-I) and -II (XT-II) (EC 2.4.2.26) [21].

The human XT-I and XT-II are type II transmembrane proteins, which are encoded by the genes XYLT1 and XYLT2. Besides their similarities regarding enzyme function, their genes are differentially expressed in tissues [22,23]. Despite the intracellular localisation of the XT-I, the enzyme is shed from the membrane of the Golgi apparatus by an unknown mechanism that involves a cysteine protease [24]. The XT activity can be measured in the human serum and provides a reliable indicator for the present rate of PG biosynthesis and is a useful serum biomarker for the assessment of fibrotic processes in patients with SSc [25]. Additional studies using human primary fibroblasts as key players of ECM remodelling and tissue repair, have shown that XYLT1 mRNA expression und extracellular XT activity correlates with the content of differentiated myofibroblasts measured by former myofibroblast marker $\alpha$-smooth muscle actin ( $\alpha$-SMA) or expression of ACTA2. Furthermore, TGF $\beta 1$ treatment of this cells leads to an increase in XYLT1 expression and XT activity while XYLT2 expression is unchanged after pro-fibrotic stimuli [26]. Therefore, XT-I expression is associated with persisting fibrosis and can be used as a myofibroblast differentiation marker [26,27]. However, little is known regarding the differential expressional regulation of both XT isoforms. Promoter analysis of XT-I revealed several transcription factor-binding sites for specificity protein 1 (SP1), early growth response factors (EGR) and Krueppel-like transcription factors (KLF), while the XYLT2 promoter provides binding sites for SP1 family members. Interestingly, sequence analysis of the genomic DNA of 100 healthy blood donors revealed one single nucleotide variant (SNV), c.-1088C >A, in the XYLT1 promoter region with an allele frequency of $38 \%$ that significantly reduced basal promoter activity by generation of a potential Smad 3 binding site, but did not contribute to the measured serum XT activity of the donors [28-30].

Giving the missing link between XYLT1 promoter analysis, identified transcription factors and the upstream cellular signalling mediating XT-I expression under fibrotic conditions, primary fibroblast cells provide a suitable model to study the relationship between exogenous pro-fibrotic stimuli and the underlying signal transduction pathways, which mediate the XT-I expression in PG biosynthesis and dermal myofibroblast differentiation. 


\section{Materials and Methods}

\subsection{Cell Culture}

Adult normal human dermal fibroblasts (NHDF) from 37- to 50-year-old women and 45- to 57-year-old men were obtained from Genlantis (San Diego, CA, USA), Cambrex (Walkerville, MI, USA) and Coriell (Camden, NJ, USA). NHDF were maintained as monolayer cultures in $100 \mathrm{~mm} \times 20$ mm cell culture dishes with Dulbecco's modified Eagle's medium (DMEM; Thermo Fisher Scientific, San Diego, CA, USA) supplemented with 10\% (v/v) foetal calf serum (Biowest, Nuaillé, France), $4 \mathrm{mmol} / \mathrm{L}$ l-glutamine and 100,000 U/L penicillin, $100 \mathrm{mg} / \mathrm{L}$ streptomycin, $0.25 \mathrm{mg} / \mathrm{L}$ amphotericin B (PAN Biotech, Aidenbach, Germany) at $37^{\circ} \mathrm{C}, 5 \% \mathrm{CO}_{2}$. Cells were used in Passage 4-9, corresponding to a cumulative population doubling levels of 7 to 17 . Therefore, primary NHDF were subcultured with an expansion ratio not exceeding 1:3 upon near confluence using 0.05\% trypsin (PAN Biotech, Aidenbach, Germany).

\subsection{Cytokine and Inhibitor Treatment}

To investigate the effect of the cytokines and inhibitors, NHDF were cultured for $24 \mathrm{~h}$ before treatment using a formerly established cell culture model [26]. In brief, cells were cultivated with a low density of 50 cells per $\mathrm{mm}^{2}$ on a hard tissue culture substrate $(100 \mathrm{~mm} \times 20 \mathrm{~mm}$ dish), promoting their trans-differentiation into proto-myofibroblasts. To avoid the effect of serum and to synchronize the cells, after an incubation time of $24 \mathrm{~h}$ fibroblasts were washed with Dulbecco's phosphate-buffered saline (Thermo Fisher, San Diego, CA, USA) and maintained in serum-free DMEM unless otherwise stated. After $24 \mathrm{~h}$, serum-starved cells were treated with $1 \mu \mathrm{g} / \mathrm{L}, 10 \mu \mathrm{g} / \mathrm{L}$ or $50 \mu \mathrm{g} / \mathrm{L}$ human recombinant activin A (HumanZyme Inc., Chicago, IL, USA), or $5 \mu \mathrm{g} / \mathrm{L}$ or $10 \mu \mathrm{g} / \mathrm{L}$ human recombinant TGF $\beta 1$ for 3, 6, 24, 48 or $120 \mathrm{~h}$. For inhibition studies final inhibitor concentrations of $10 \mu \mathrm{mol} / \mathrm{L}$ or $50 \mu \mathrm{mol} / \mathrm{L}$ SB431542 (Miltenyi Biotec GmbH, Bergisch Gladbach, Germany), $25 \mu \mathrm{mol} / \mathrm{L}$ SP600125, $10 \mu \mathrm{mol} / \mathrm{L}$ UO126, $20 \mu \mathrm{mol} / \mathrm{L}$ SB203580 (Cell Signaling Technology Inc., Danvers, MA, USA) or $10 \mu \mathrm{mol} / \mathrm{L}$ SIS3 (Merck KGaA, Darmstadt, Germany) diluted in serum-free DMEM were used. All inhibitors were dissolved in dimethyl sulfoxide or water and used according to the manufacturer's instructions. Negative controls treated with solvent or vehicle were included for every sampling time. All experiments were performed in biological triplicates per number $(n)$ of donor-derived primary cultures.

\subsection{Nucleic Acid Extraction and Synthesis of Complementary DNA}

Total RNA was extracted from cells using the RNA Spin Blood kit (Machery-Nagel, Düren, Germany) according to the manufacturer's instructions. DNA extraction was performed using the DNA Spin Blood kit (Machery-Nagel, Düren, Germany). The NanoDrop 2000 spectrophotometer (Peqlab Erlangen, Germany) was used for measuring nucleic acid concentrations. An amount of $1 \mu \mathrm{g}$ of total RNA was reverse transcribed into complementary DNA (cDNA) utilizing the SuperScript II Reverse Transcriptase kit (Thermo Fisher, Waltham, MA, USA) and diluted to 1:10 prior to storage at $-20^{\circ} \mathrm{C}$ or analysis.

\subsection{Real-Time Polymerase Chain Reaction Analysis}

Quantitative real-time polymerase chain reaction (qRT-PCR) analysis was performed in triplicate per gene and cDNA sample using $2.5 \mu \mathrm{L}$ of diluted cDNA and $7.5 \mu \mathrm{L}$ LightCycler 480 SYBR Green I master mix (Roche, Basel, Switzerland) and gene-specific forward and reverse primers at a final concentration of $0.625 \mu \mathrm{mol} / \mathrm{L}$. The intron-spanning primer sequences are listed in Table 1. The plate-based real-time PCR amplification, detection and melting curve analysis of generated PCR products were performed using a LightCycler 480 Instrument II system (Roche, Basel, Switzerland). For PCR, 40 cycles of denaturation for $10 \mathrm{~s}$ at $95^{\circ} \mathrm{C}$, annealing for $15 \mathrm{~s}$ at $59{ }^{\circ} \mathrm{C}$ or $63{ }^{\circ} \mathrm{C}$, followed by a thermal dissociation protocol for SYBR green detection was performed. For reaction validation and gene expression analysis the LightCycler 480 Instrument Operator's Manual Software Version 
1.5.1 was used (Roche, Basel, Switzerland). The sample mRNA expression normalization was done with an internal control gene index consisting of the geometric mean of the expression level of the housekeeping genes succinate dehydrogenase complex, subunit $\mathrm{A}$, flavoprotein variant $(S D H A)$, ribosomal protein L13a (RPL13A) and $\beta 2$-microglobulin $(B 2 M)$. The relative mRNA expressions of the target genes were determined by the comparative delta-delta $C_{T}$ method considering the PCR efficiency of the gene of interest and the internal control genes [31].

Table 1. Primer sequences and annealing temperatures $\left(\mathrm{T}_{\mathrm{A}}\right)$ used for $\mathrm{qRT}-\mathrm{PCR}$ analysis.

\begin{tabular}{|c|c|c|c|}
\hline Gene & Primers & $\mathrm{T}_{\mathrm{A}}\left({ }^{\circ} \mathrm{C}\right)$ & Product Size (bp) \\
\hline ACTA2 & $\begin{array}{l}\text { 5'-GACCGAATGCAGAAGGAG-3' } \\
5^{\prime} \text {-CGGTGGACAATGGAAGG-3' }\end{array}$ & 59 & 169 \\
\hline$B 2 M$ & $\begin{array}{l}\text { 5'-TGTGCTCGCGCTACTCTCTCTT-3' } \\
5^{\prime} \text {-CGGATGGATGAAACCCAGACA-3' }\end{array}$ & 59 & 137 \\
\hline RPL13A & $\begin{array}{l}\text { 5'-CGGAAGGTGGTGGTCGTA-3' } \\
5^{\prime} \text {-CTCGGGAAGGGTTGGTGT-3' }\end{array}$ & 63 & 165 \\
\hline SDHA & $\begin{array}{l}\text { 5'-AACTCGCTCTTGGACCTG-3' } \\
\text { 5'-GAGTCGCAGTTCCGATGT-3' }\end{array}$ & 63 & 177 \\
\hline SMAD2 & $\begin{array}{l}5^{\prime} \text {-ACAACAGGCCTTTACAGCTTCT-3' } \\
5^{\prime} \text {-GGAGGCAAAACTGGTGTCTCA-3' }\end{array}$ & 63 & 239 \\
\hline SMAD3 & $\begin{array}{l}5^{\prime} \text {-ACCATCCGCATGAGCTTC-3' } \\
5^{\prime} \text {-CACTGCAAAGGCCCATTC-3' }\end{array}$ & 63 & 107 \\
\hline SMAD7 & $\begin{array}{l}\text { 5'-AGATGCTGTGCCTTCCTC-3' } \\
\text { 5'-GTCTTCTCCTCCCAGTATGC-3' }\end{array}$ & 63 & 135 \\
\hline TGFB1 & $\begin{array}{l}\text { 5'-GCGATACCTCAGCAACC-3' } \\
\text { 5'-ACGCAGCAGTTCTTCTCC-3' }\end{array}$ & 59 & 331 \\
\hline XYLT1 & 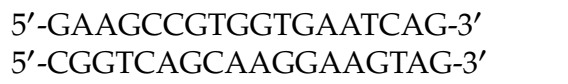 & 63 & 281 \\
\hline XYLT2 & $\begin{array}{l}\text { 5'-ACACAGATGACCCGCTTGTGG-3' } \\
5^{\prime} \text {-TTGGTGACCCGCAGGTTGTTG-3' }\end{array}$ & 63 & 139 \\
\hline
\end{tabular}

\subsection{Small Interfering RNA Transfection}

For targeted gene silencing, small interfering RNA (siRNA) delivery into NHDF was performed by reverse transfection using the Lipofectamine 2000 transfection reagent (Thermo Fisher, San Diego, CA, USA). NHDF were maintained in antibiotic-free medium $\left(2.9 \times 10^{5}\right.$ cells, $60 \mathrm{~mm} \times 50 \mathrm{~mm}$ dish $)$ and reverse transfected with the transfection mixture containing one of two separate silencer pre-designed siRNAs targeting Smad2, Smad3, Smad7 or a non-targeting, fluorescently labelled negative control siRNA diluted in Opti-MEM I Reduced Serum Medium (Thermo Fisher, San Diego, CA, USA) to yield a final siRNA concentration of 40-100 nmol/L per well. A total of $24 \mathrm{~h}$ post-transfection the siRNA transfection efficiency was monitored by fluorescence microscopy. A transfection efficiency of nearby $100 \%$ was considered for data analysis. When compared with negative control siRNA the siRNA that provided the most efficient inhibition per target gene determined via qRT-PCR was used for future experiments. For activin A treatment, transfected cells were serum-starved for $16 \mathrm{~h}$ and maintained in activin A-supplemented media for $6 \mathrm{~h}$ until cell lysis.

\subsection{Radiochemical Xylosyltransferase Activity Assay}

The determination of intracellular XT activity from cell lysates and extracellular enzyme activity from cell supernatants was performed by radiochemical determination of the enzyme-catalysed incorporation of UDP-[ $\left.{ }^{14} \mathrm{C}\right]-\mathrm{d}$-xylose (PerkinElmer, Foster City, CA, USA) into a silk fibroin acceptor protein as previously described [32]. The quantified disintegrations per minute (dpm) were referred to total DNA sample content and resemble the quantity of incorporated UDP- $\left[{ }^{14} \mathrm{C}\right]-\mathrm{d}-\mathrm{xyl}$ lose, which is proportional to the sample XT activity. For sample preparation of the extracellular XT activity the cell culture supernatant was collected, whereas for intracellular samples the same cell culture monolayer was lysed using $0.75 \mathrm{~mL}$ of a Nonidet P-40 (NP-40)-based buffer (50 mM TRIS, 150 mM 
$\mathrm{NaCl}, 1 \% \mathrm{NP}-40, \mathrm{pH} 7.8)$. After sample centrifugation $\left(10,000 \times g, 10 \mathrm{~min}\right.$ at $\left.4{ }^{\circ} \mathrm{C}\right)$, the supernatant was collected and stored at $-20^{\circ} \mathrm{C}$ until usage. The enzyme activities were measured $48 \mathrm{~h}$ and $120 \mathrm{~h}$ after cytokine treatment.

\subsection{Statistical Analysis}

The data are presented as mean values \pm standard error of the mean (SEM). Statistical analysis of the variance between the experimental conditions was evaluated by non-parametric two-tailed Mann-Whitney U-tests using GraphPad Prism 7.0 (GraphPad Software, La Jolla, CA, USA) software. The lack of a Gaussian distribution was confirmed by checking normality visually (frequency distribution histogram) as well as by computing the Shapiro-Wilk normality test. The probability (P) values of less than 0.05 were considered as statistically significant. In the figures, the $P$ values are indicated with asterisks and horizontal lines that connect the compared bars. Asterisks directly above the error bars of the treatment group indicate statistical differences between the treatment and control group, respectively.

\section{Results}

\subsection{Identification of Pro-Fibrotic Mediators Regulating XT-I Expression in Fibroblasts}

Previous work has demonstrated that TGF $\beta 1$ is a potent inducer of the XT-I gene and protein expression in primary human dermal and cardiac fibroblasts $[26,27]$. We wanted to examine whether other pro-fibrotic cytokines and growth factors are able to modulate XYLT1 and XYLT2 mRNA expression of skin fibroblasts. Using a formerly established cell culture model [26], NHDF were incubated with recombinant human TGF $\beta 1$ or different cytokines and growth factors (Figure S1). After $48 \mathrm{~h}$ of incubation we found significant increased activity and mRNA levels of myofibroblast marker XT-I (5.1 \pm 0.9-fold and $4.2 \pm 0.9$-fold, both $p<0.0001$; Figure S1A,B) and ACTA2 mRNA level $(2.4 \pm 0.9, p<0.0001$; Figure S1C) in activin A-treated cells compared to the untreated controls, whereas no changes in XYLT2 mRNA expression were observed ( $p=0.06$; Figure S1D). We were unable to demonstrate changes in XT activity or XYLT1 mRNA expression after stimulation of NHDF with connective tissue growth factor (CTGF), angiotensin-II or endothelin-1 and could only show that some of them were able to exert regulatory effects on TGF $\beta 1$-induced XT-I expression (Figure S1A,B). The treatment of NHDF with cytokines IL-4, IL-6 or IL-13 alone did not increase XYLT1 mRNA expression either (Figure S2).

In comparison to TGF $\beta 1$ treatment, activin A-mediated XYLT1 mRNA and XT activity regulation seemed to be less pronounced $(7.7 \pm 1.3$-fold and $5.1 \pm 0.9$-fold vs. $4.2 \pm 0.9$-fold and $5.1 \pm 0.9$-fold, all $p<0.0001$; Figure S1A,B). For direct comparison of the TGF $\beta 1$ and activin A-mediated effects, serum-starved NHDF were treated with the same TGF $\beta 1$ and activin A concentration of $10 \mu \mathrm{g} / \mathrm{L}$ and harvested after a short incubation time of $6 \mathrm{~h}$, to minimalize the side effects due to secretion of secondary metabolites and mediators (Figure 1). Activin A treatment significantly increased XYLT1 expression $2.1 \pm 0.3$-fold ( $p=0.0018$ ), whereas treatment with TGF $\beta 1$ revealed a $6.9 \pm 1.1$-fold $(p<0.0001)$ increase of XYLT1 expression (Figure 1A). In contrast, no stimulating effects $(p=0.46)$ could be observed for XYLT2 mRNA expression after activin A or TGF $\beta 1$ treatment of NHDF (Figure 1B). In order to investigate whether the induction of TGFB1 transcripts may play a role in activin A-mediated XYLT1 regulation, the TGFB1 mRNA expression changes after TGF $\beta 1$ and activin A treatment of NHDF were observed. While activin A treatment had no significant effect $(p=0.25)$ compared to the control, TGF $\beta 1$ significantly auto-induced its mRNA expression $2.3 \pm 0.3$-fold $(p<0.0001)$ (Figure $1 \mathrm{C}$ ). Taken together, these results show that activin A is a TGF $\beta 1$-independent inducer of XYLT1 mRNA expression and XT activity in NHDF. 

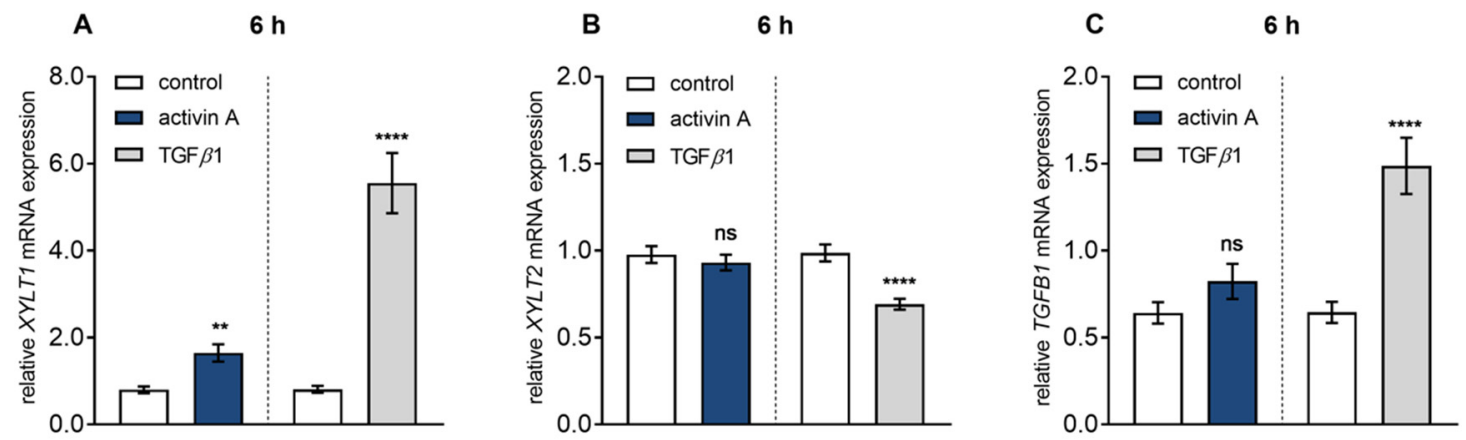

Figure 1. TGF $\beta$ superfamily cytokine regulated XYLT isoform and TGFB1 mRNA expression. Human primary fibroblasts $(n=3)$ were cultured the day before the experiment. Cells were serum-starved for $24 \mathrm{~h}$ and treated with activin A (10 $\mu \mathrm{g} / \mathrm{L}$; left side) or TGF $\beta 1$ (10 $\mu \mathrm{g} / \mathrm{L}$; right side) for $6 \mathrm{~h}$. The dashed line indicated that the activin A and TGF $\beta 1$ experiments were performed independently. Relative XYLT1 (A), XYLT2 (B) or TGFB1 (C) mRNA expression levels were analysed by quantitative real-time PCR. Shown values are means \pm SEM for three biological and three technical replicates per experiment. Mann-Whitney $U$ test: not significant (ns), $p<0.05\left(^{*}\right), p<0.01\left(^{* *}\right), p<0.001\left(^{* * *}\right)$, $\left.p<0.0001{ }^{* * * *}\right)$.

\subsection{Activin A Induces Transient XYLT1 mRNA Expression and XT Activity Increase via ACVRIB/ALK4}

Showing that activin $A$ is a potent inducer of XYLT1 expression under fibrotic conditions, we further examined the response of NHDF to various activin A concentrations in time-course experiments (Figure 2). The XYLT1 mRNA expression levels were quantified $3 \mathrm{~h}, 6 \mathrm{~h}$ and $24 \mathrm{~h}$ post-treatment by qRT-PCR analysis (Figure 2A). The NHDF showed an early up-regulation of the XYLT1 mRNA level at $3 \mathrm{~h}$ of activin A treatment at concentrations of $10 \mu \mathrm{g} / \mathrm{L}$ and $50 \mu \mathrm{g} / \mathrm{L}$ of $1.3 \pm 0.3$-fold $(p=0.01)$ and $2.3 \pm 0.5$-fold $(p<0.0001)$. This initial rise in XYLT1 mRNA expression after $3 \mathrm{~h}$ was followed by a more pronounced expression increase in $10 \mu \mathrm{g} / \mathrm{L}$ and $50 \mu \mathrm{g} / \mathrm{L}$ activin A-treated cells of $2.7 \pm$ 0.3 -fold $(p<0.0001)$ and $3.4 \pm 0.4$-fold $(p<0.0001)$ after $6 \mathrm{~h}$ in comparison to the untreated control fibroblasts. In comparison to control cells, activin A treatment at concentrations of $10 \mu \mathrm{g} / \mathrm{L}$ and $50 \mu \mathrm{g} / \mathrm{L}$ for $24 \mathrm{~h}$ increased the XYLT1 expression level $1.9 \pm 0.3$-fold $(p=0.0002)$ and $3.2 \pm 0.6$-fold $(p<0.0001)$, respectively. The treatment with $1 \mu \mathrm{g} / \mathrm{L}$ activin A resulted in a $1.2 \pm 0.1$-fold $(p=0.01)$ increase in XYLT1 mRNA expression after $6 \mathrm{~h}$, though no expression changes were detectable after $3 \mathrm{~h}$ and $24 \mathrm{~h}$ treatment compared to the control (Figure 2A). These results demonstrate that activin A increases XYLT1 mRNA expression in a time- and concentration-dependent manner in NHDF.

To confirm that the changes in XYLT1 mRNA expression observed were caused by activin A treatment, cells were separately or simultaneously treated with the ALK4 inhibitor SB431542 [33,34] and activin A for $6 \mathrm{~h}$ (Figure 2B). The results showed that activin A induced a $2.1 \pm 0.3$-fold $(p=0.002)$ increase in XYLT1 mRNA expression compared to the control that was completely abrogated by SB431542. Moreover, the single treatment of fibroblasts with SB431542 did not alter XYLT1 basal expression $(p=0.79)$ compared to the vehicle-treated control cells. Treatment of NHDF with activin A or SB431542 did not alter XYLT2 mRNA expression (Figure 2B). Together these results show an isoform-specific increase in XYLT1 mRNA expression by activin A involving the ALK4 receptor.

Despite intracellular localization of XT-I, more than $90 \%$ of its enzyme activity is found in the culture supernatant, accumulating over time [25]. To examine if activin A-induced stimulation of XYLT1 gene expression correlates with the changes in enzyme activity, extracellular and intracellular $\mathrm{XT}$ activity of NHDF were measured by radiochemical enzyme assay (Figure 2C,D). For this purpose, NHDF were treated with $10 \mu \mathrm{g} / \mathrm{L}$ and $50 \mu \mathrm{g} / \mathrm{L}$ activin A for $48 \mathrm{~h}$ and $120 \mathrm{~h}$ to promote detectable enzyme accumulation in the cell culture supernatant. In comparison to the untreated cells, the supplementation of activin A at different concentrations for $48 \mathrm{~h}$ increased the extracellular XT activity of NHDF 1.6 \pm 0.3 -fold $(p=0.03 ; 10 \mu \mathrm{g} / \mathrm{L})$ and $1.5 \pm 0.3$-fold $(p=0.03 ; 50 \mu \mathrm{g} / \mathrm{L})$, respectively. When analysing the XT activity from the corresponding cell lysates of former activin A-treated cells, a $1.7 \pm 0.7$-fold 
$(p=0.02 ; 10 \mu \mathrm{g} / \mathrm{L})$ and $1.8 \pm 0.7$-fold $(p=0.04 ; 50 \mu \mathrm{g} / \mathrm{L})$ enhancement in intracellular XT activity was detectable in comparison to the untreated controls (Figure 2C). Compared to the untreated control cells after $120 \mathrm{~h}$, no inducible effects regarding extra- and intracellular XT activity were observed after incubation of NHDF with the activin A concentration of $10 \mu \mathrm{g} / \mathrm{L}$. The activin A treatment of NHDF with a concentration of $50 \mu \mathrm{g} / \mathrm{L}$ increased the extracellular XT activity $1.7 \pm 0.3$-fold $(p=0.04)$, while the intracellular enzyme activity was significantly raised, $1.6 \pm 0.2$-fold $(p=0.001)$ (Figure 2D). In agreement with the gene expression data (Figure 2B), the usage of the ALK4 inhibitor SB431542 suppressed the activin A-mediated increase in extra- and intracellular XT activity (Figure 2C,D). These results reveal that the activin A-induced XYLT1 mRNA expression increase correlates time- and concentration-dependently with the changes in the extracellular and intracellular XT activity of NHDF.
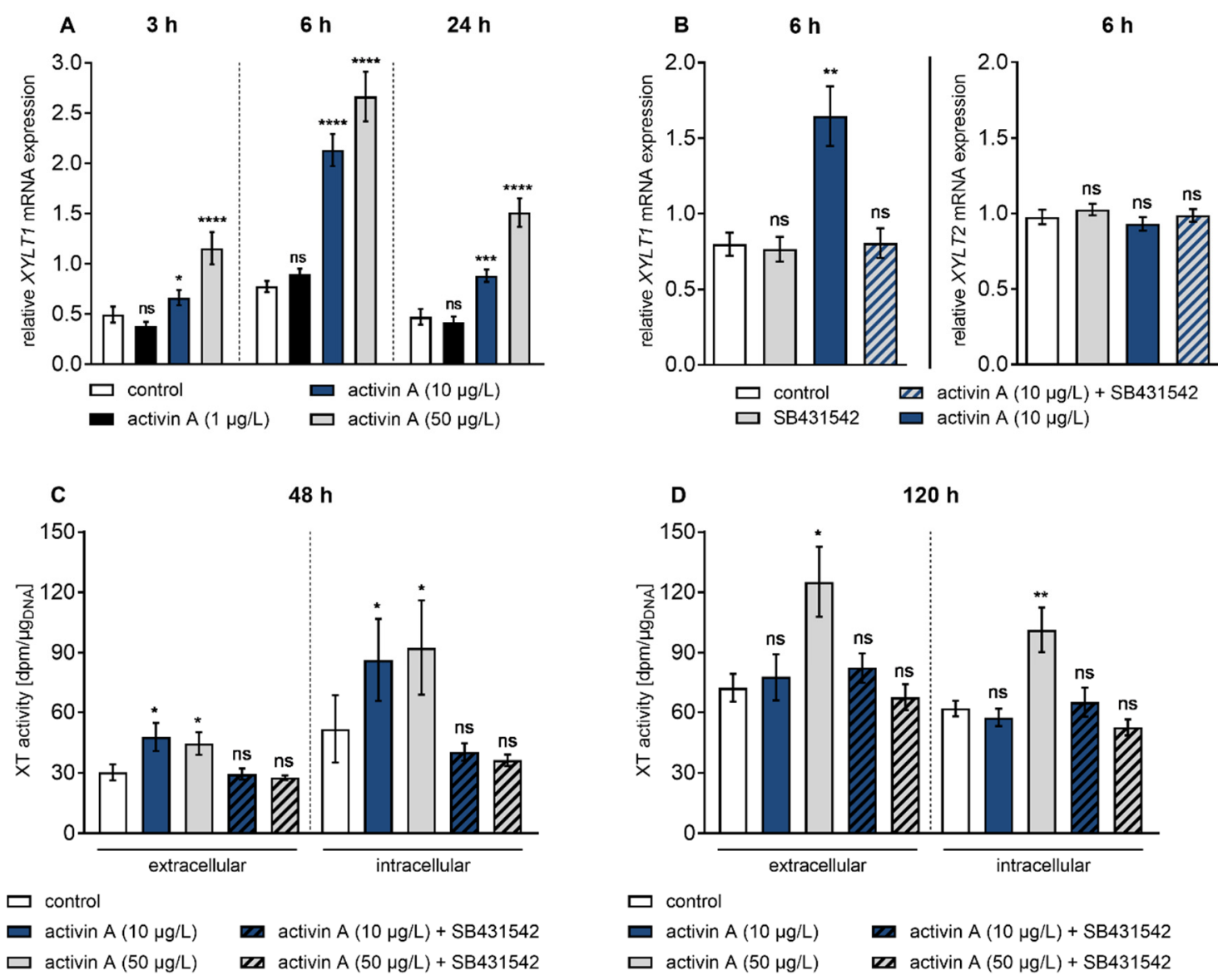

Figure 2. Time course of activin A-regulated XYLT1 mRNA expression and XT activity. Human primary fibroblasts $(n=3)$ were cultured the day before the experiment. Cells were serum-starved for $24 \mathrm{~h}$ and treated with activin A or with activin A and the ALK4 inhibitor SB431542 $(10 \mu \mathrm{mol} / \mathrm{L})$ for the indicated time points. (A,B) Relative mRNA expression levels were analysed by quantitative real-time PCR. Shown values are means \pm SEM for three biological and three technical replicates per donor-derived primary cell culture. Mann-Whitney $U$ test: not significant (ns), $p<0.05\left(^{*}\right), p<0.01\left(^{* *}\right), p<0.001\left(^{(* *)}\right.$, $\left.p<0.0001{ }^{* * * *}\right)$. (C,D) XT activity was measured in cell supernatants and lysates by radiochemical enzyme assay and expressed as dpm per $\mu \mathrm{g}$ of DNA. Shown values are means \pm SEM for three biological and one technical replicate per experiment. Mann-Whitney $U$ test: not significant (ns), $p<0.05\left({ }^{*}\right)$, $\left.p<0.01{ }^{* *}\right)$.

\subsection{ALK4-Activin A-Mediated XYLT1 mRNA Expression Requires MAPK Signalling Pathways}

In order to understand the molecular mechanism of activin A-ALK4-mediated XT-I induction in NHDF, we investigated the underlying signalling pathways utilizing small-molecule inhibitors. The role of MAPK pathway on activin A-stimulated XYLT1 expression was addressed by using 
SP600125, a broad-spectrum inhibitor of JNK [35]; SB203580, inhibitor of p38 MAPK [36]; and UO126, a highly selective ERK inhibitor [37] on NHDF in presence or absence of activin A (Figure 3).
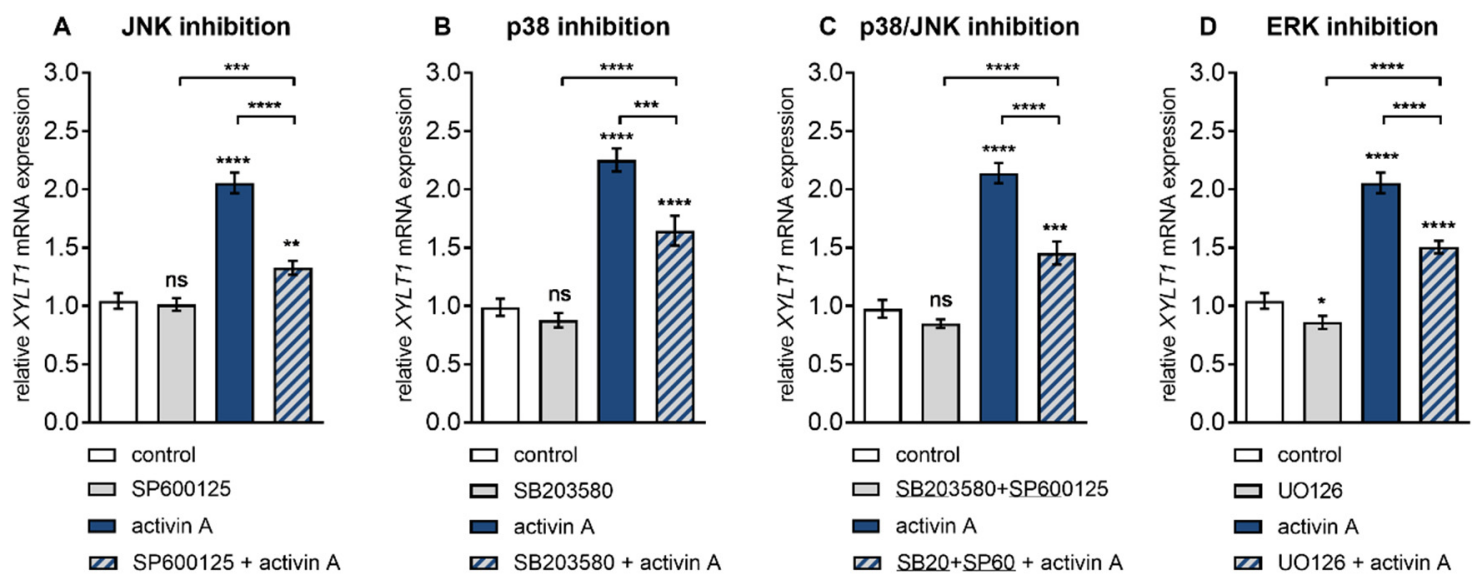

Figure 3. Inhibition of activin A-induced XYLT1 mRNA expression by small-molecule inhibitors of MAPK pathways. Human primary fibroblasts $(n=3)$ were cultured the day before the experiment. Cells were serum-starved for $24 \mathrm{~h}$ and treated with or without activin A (10 $\mu \mathrm{g} / \mathrm{L})$ and (A) JNK inhibitor

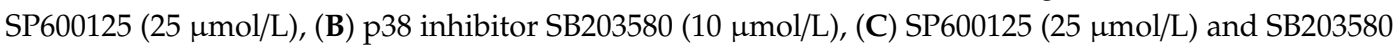
$(10 \mu \mathrm{mol} / \mathrm{L})$ or (D) ERK inhibitor UO126 $(10 \mu \mathrm{mol} / \mathrm{L})$ for $6 \mathrm{~h}$. Relative mRNA expression level of XYLT1 was analysed by qRT-PCR. Shown values are means \pm SEM for three biological and three technical replicates per experiment. Mann-Whitney $U$ test: not significant (ns), $p<0.05\left(^{*}\right), p<0.01\left({ }^{* *}\right), p<0.001$ $\left.\left.{ }^{* * *}\right), p<0.00011^{* * * *}\right)$.

We found that the activin A-mediated increases in XYLT1 expression at $6 \mathrm{~h}$ post treatment could be diminished by JNK inhibitor SP600125 and p38 MAPK inhibitor SB203580 in a concentration-dependent manner (data not shown). Both, SP600125 and SB203580 significantly reduced activin A-induced XYLT1 expression increase $(2.3 \pm 0.2$-fold, $p<0.0001) 0.6 \pm 0.04$-fold $(p<0.0001)$ and $0.7 \pm 0.1$-fold $(p=0.0007)$, respectively (Figure $3 \mathrm{~A}, \mathrm{~B})$. In the presence of both particular inhibitors no regulatory effects regarding the basal expression of XYLT1 (Figure 3A,B) and XYLT2 (Figure S3A,B) were observed compared to the vehicle-treated control cells. Combinatory treatment of NHDF with JNK inhibitor SP600125 and p38 MAPK inhibitor SB203580 resulted in a significantly decreased activin A-mediated XYLT1 mRNA level increase of $0.7 \pm 0.05$-fold $(p<0.0001)$ (Figure 3C). In the presence of both inhibitors no regulatory effects regarding the basal expression of XYLT1 (Figure 3C) and XYLT2 (Figure S3C) mRNA were observed compared to the vehicle-treated control cells.

In comparison to the vehicle and ERK inhibitor UO126 exclusively treated cells, the presence of activin A resulted in a particular $2 \pm 0.1$-fold $(p<0.0001)$ and $1.8 \pm 0.1$-fold $(p<0.0001)$ up-regulation of XYLT1 mRNA expression, respectively (Figure 3D). Moreover, UO126 significantly decreased the basal XYLT1 expression $0.8 \pm 0.08$-fold $(p=0.03)$ and the activin A-induced XYLT1 expression increased ( $2 \pm 0.1$-fold, $p<0.0001) 0.7 \pm 0.04$-fold $(p<0.0001)$ of that of the respective controls (Figure 3D). In addition, we found a decreased basal mRNA expression of XYLT2 of $0.9 \pm 0.03$-fold $(p=0.002)$ in UO126 inhibitor single-treated cells compared with those with the vehicle treatment (Figure S3D). These data show the involvement of MAPK JNK, p38 and ERK in ALK4-activin A-mediated XYLT1 expression. Furthermore, the results indicate a role for MAPK ERK in the maintenance of basal XYLT1 and XYLT2 mRNA expression in NHDF.

\subsection{Smad3 is Dispensable for Activin A-Induced XYLT1 mRNA Expression in NHDF}

Earlier studies by Takagi et al. on NHDF showed an activin A-induced $(10 \mu \mathrm{g} / \mathrm{L})$ phosphorylation of Smad2/3 after $4 \mathrm{~h}$ cytokine treatment [10]. On the basis of these findings, we wanted to verify the 
impact of the canonical Smad pathway on basal XYLT1 and XYLT2 mRNA expression as well as on activin A-stimulated XYLT1 expression increase by using siRNA knockdown experiments (Figure 4).
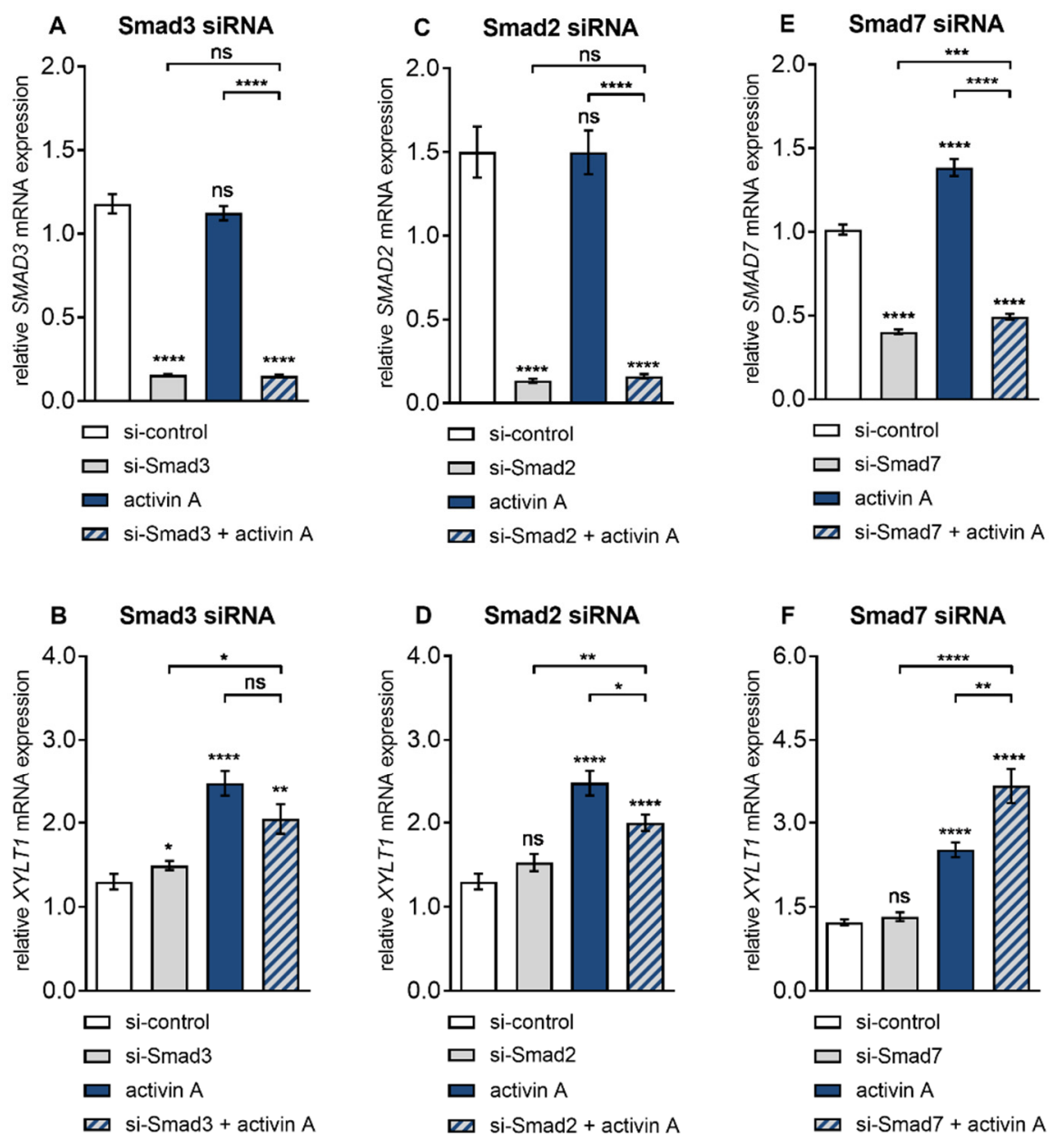

Figure 4. Basal and activin A-induced XYLT1 mRNA expression were marginally affected by siRNA-mediated Smad knockdown. Human primary fibroblasts $(n=3)$ were cultured for $24 \mathrm{~h}$ before transfection with a negative control siRNA (si-control, 50 or $100 \mathrm{nmol} / \mathrm{L}$ ) or siRNA targeting against (A,B) Smad3 (si-Smad3, $50 \mathrm{nmol} / \mathrm{L}),(\mathbf{C}, \mathbf{D})$ Smad2 (si-Smad2, $50 \mathrm{nmol} / \mathrm{L})$ or (E,F) Smad7 (si-Smad7, $100 \mathrm{nmol} / \mathrm{L}$ ). A total of $24 \mathrm{~h}$ post-transfection, cells were serum-starved for $16 \mathrm{~h}$ and treated with or without activin A $(10 \mu \mathrm{g} / \mathrm{L})$ for $6 \mathrm{~h}$. Relative XYLT1 and SMAD2/3/7 mRNA expression levels were analysed by qRT-PCR. Shown values are means \pm SEM for three biological and three technical replicates per experiment. Mann-Whitney $U$ test: not significant (ns), $p<0.05\left(^{*}\right), p<0.01\left({ }^{* *}\right), p<0.001$ $\left.\left.{ }^{* * *}\right), p<0.00011^{* * * *}\right)$.

After Smad3 siRNA transfection, the basal SMAD3 expression of the NHDF cells was knocked down $0.1 \pm 0.01$-fold $(p<0.0001)$, which did not change by additional activin A treatment compared to the negative control siRNA transfected cells (Figure 4A). Moreover, the Smad3 knockdown was selective, not affecting the expression levels of Smad2 or Smad7 (data not shown). Smad3 siRNA transfected NHDF showed an increased basal XYLT1 expression of $1.1 \pm 0.09$-fold $(p=0.02)$ compared to the negative control siRNA transfected cells. Activin A treatment of control siRNA transfected NHDF resulted in a significant induction of XYLT1 expression of $1.9 \pm 0.2$-fold $(p<0.0001)$. This induction did not significantly change $(p=0.08)$ in the presence of Smad3 knockdown. Therefore, Smad3 siRNA transfected NHDF treated with activin A exhibited an increased XYLT1 expression of 1.6 \pm 0.2 -fold $(p=0.02)$ compared to the untreated control cells (Figure 4B). In contrast to basal XYLT1 expression, the basal XYLT2 expression level of Smad3 siRNA transfected cells fall below that of the respective 
siRNA controls $(0.7 \pm 0.02$-fold, $p<0.0001)$ (Figure S4A). These results demonstrate that the induction of XYLT1 expression by activin A is Smad3-independent, while basal XYLT1 and XYLT2 expression were reversely regulated by $S M A D 3$ expression.

After showing the dispensability of SMAD3 in activin A-induced XYLT1 expression we addressed the role of Smad2 in this context with the same experimental approach. NHDF transfected with Smad2 siRNA exhibited a highly significant SMAD2 transcription decrease of $0.1 \pm 0.01$-fold $(p<0.0001)$ compared to negative control siRNA-treated cells, which did not change due to activin A supplementation (Figure 4C). Specific Smad2 siRNA knockdown in NHDF did not alter basal XYLT1 expression $(p=0.08)$ compared to the negative control siRNA transfected cells, whereas the activin A-mediated XYLT1 mRNA expression increase $(1.9 \pm 0.2$-fold, $p<0.0001)$ was significantly diminished $0.8 \pm 0.06$-fold $(p<0.02)$ (Figure $4 \mathrm{D})$. In comparison to the controls, the transfection of NHDF with Smad2 siRNA significantly up-regulated the basal XYLT2 mRNA expression $1.2 \pm 0.05$-fold $(p<0.0001)$ (Figure S4B). These findings show that the induction of XYLT1 expression by activin A is dependent on Smad2, whereas basal XYLT1 expression is Smad2-independent. Furthermore, these results demonstrate a suppressive role of Smad2 on basal XYLT2 expression in NHDF.

To confirm the results of differential and antagonistic regulation of basal and activin A regulated XYLT1 and XYLT2 mRNA expression by Smad2 and Smad3 we increased the cellular availability of activated Smads 2 and 3 by selective downregulation of Smad inhibitor Smad7. Activin A treatment for $6 \mathrm{~h}$ resulted in an increase in SMAD7 expression of $1.4 \pm 0.06$-fold $(p<0.0001)$ compared to the untreated control cells. Compared to the negative control siRNA treatment of NHDF, the basal and activin A-induced SMAD7 expression was decreased by Smad7 siRNA knockdown to a similar extend, $0.4 \pm 0.01$-fold $(p<0.0001)$ and $0.5 \pm 0.02$-fold $(p<0.0001)$, respectively (Figure 4E). Basal XYLT1 expression was unaffected $(p=0.19)$ by Smad7 siRNA transfection compared to the negative control siRNA treated cells. The activin A treatment for $6 \mathrm{~h}$ significantly induced XYLT1 expression $2 \pm 0.1$-fold $(p<0.0001)$ compared to untreated controls. This activin A-induced XYLT1 expression increase was significantly enhanced $1.5 \pm 0.1$-fold $(p<0.004)$ after Smad7 deletion. Smad7 siRNA transfected NHDF treated with activin A exhibited an increased XYLT1 expression of $2.8 \pm 0.3$-fold $(p<0.004)$ compared to the untreated control cells (Figure 4F). In contrast to the basal expression of XYLT1, basal XYLT2 mRNA expression was induced $1.3 \pm 0.05$-fold $(p<0.0001)$ after Smad7 knockdown compared to the controls (Figure S4C). These results demonstrate that the induction of XYLT1 expression by activin A can be enhanced by unavailability of Smad7. Additionally, the results show an inhibitory role of Smad7 on basal XYLT2 expression in NHDF, while basal XYLT1 expression is independent of SMAD7 expression.

The finding that Smad3 inhibition by siRNA-mediated gene knockdown failed to properly impair activin A-induced XYLT1 expression in NHDF was independently confirmed by pharmacologic Smad3 inhibitor SIS3 (Figure 5), which has been shown in previous works not to inhibit the Smad2 or MAPK pathways in human fibroblasts [38]. Compared to the vehicle-treated cells, the presence of SIS3 increased the basal XYLT1 expression $2.1 \pm 0.5$-fold $(p=0.048)$ at $6 \mathrm{~h}$ post-treatment. NHDF treated with activin A for $6 \mathrm{~h}$ increased the XYLT1 expression $2.6 \pm 0.5$-fold $(p<0.0001)$ of that from the untreated control cells (Figure 5A). In consistency with former results obtained from siRNA experiments (Figure 4B), the activin A-mediated expression increase in NHDF was not significantly impeded $(p=0.08)$ in the presence of the Smad3 inhibitor SIS3. In direct comparison to the SIS3 treatment alone, the activin A treatment up-regulated the XYLT1 mRNA expression 1.8 \pm 0.4 -fold $(p=0.001)$ (Figure 5A). On the contrary, there was a significant decrease in the basal XYLT2 expression of $0.6 \pm 0.04$-fold $(p<0.0001)$ in the SIS3-treated cells in comparison to the vehicle treated control cells (Figure 5B). These results confirm the former findings about Smad3 dispensability of activin A-mediated XYLT1 mRNA expression increase and its suppressive role in basal XYLT1 expression. In addition, we substantiated our findings of basal XYLT2 mRNA expression dependency on SMAD3 expression. Figure $5 \mathrm{C}$ shows a schematic diagram of these findings. 

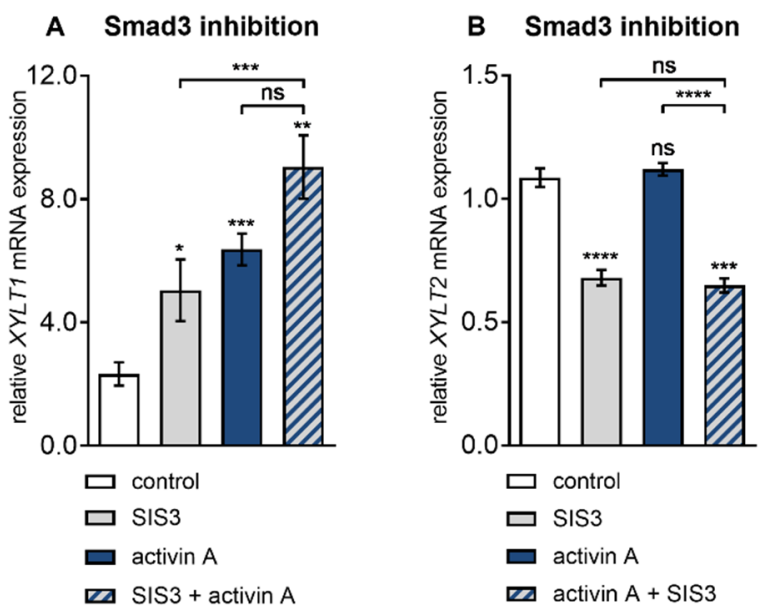

C

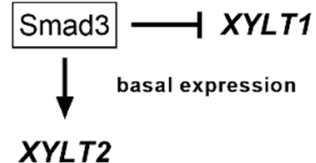

Figure 5. Differential regulation of basal XYLT isoform mRNA expression by Smad3. Human primary fibroblasts $(n=3)$ were cultured the day before the experiment. Cells were serum-starved for $24 \mathrm{~h}$ and treated with or without activin A $(10 \mu \mathrm{g} / \mathrm{L})$ in the presence or absence of the Smad3 inhibitor SIS3 $(10 \mu \mathrm{mol} / \mathrm{L})$ for $6 \mathrm{~h}$. Relative (A) XYLT1 and (B) XYLT2 mRNA expression levels were analysed by qRT-PCR. Shown values are means \pm SEM for three biological and three technical replicates per experiment. Mann-Whitney $U$ test: not significant (ns), $p<0.05\left(^{*}\right), p<0.01\left(^{* *}\right), p<0.001\left(^{* * *}\right)$,

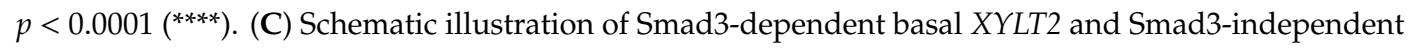
basal XYLT1 expression.

\section{Discussion}

The activity of GAG initiating key enzyme XT-I was found to be increased in the serum of patients with connective tissue diseases such as SSc or liver fibrosis [25,39]. Furthermore, long-term studies revealed that serum XT-I activity of SSc patients remains increased [25], corresponding to elevated PG metabolism and increased GAG content found in skin biopsies or cultured SSc fibroblasts $[40,41]$. Many TGF $\beta$ superfamily ligands are potent mediators of ECM deposition and are highly up-regulated under fibrotic conditions [42]. Until now, studies have described an induction of XYLT1 expression in fibrotic tissue or in cultured primary cells treated with TGF $\beta 1$, IL- $1 \beta$ or thrombin $[26,27,43-47]$, while the effect of other pro-fibrotic cytokines and their underlying signalling pathways remain unknown.

In the present study, we demonstrate for the first time that activin A, which was shown to be involved in wound healing processes and the pathogenesis of SSc [10,12], is a potent inducer of gene expression and activity of XT-I in dermal skin fibroblasts. Therefore, we provide evidence that one mechanism by which activin A contributes to dermal fibrosis in SSc is through the increase in XYLT1 expression in NHDF, the major cells responsible for ECM remodelling [48].

We found that activin A-mediated XYLT1 mRNA expression increase is time- and concentration-dependent, and considerably increased the intra- and extracellular XT enzyme activity in NHDF. The correlation of mRNA expression and enzyme activity increase regarding XT-I has been shown in this and numerous other studies using TGF $\beta 1$-treated human dermal and cardiac fibroblasts [26,27,45-47]. Furthermore, we observed, in consistency with previous results in NHDF [25], that the extracellular enzyme activity of untreated cells increased over time due to the protein accumulation in the cell supernatant, while intracellular XT activity remains constant over the test period of $120 \mathrm{~h}$. These findings support the hypothesis that two regulatory mechanisms exist to control enzyme activity in NHDF: One at the transcriptional stage and another operating post-translationally, shedding the Golgi-resident, constitutive active enzyme from the membrane for release to the extracellular space controlling the rate of PG biosynthesis by reducing the cellular enzyme amount $[24,29]$. In contrast to TGF $\beta 1$, activin A treatment of NHDF results in a weaker XYLT1 mRNA expression increase, which can be explained by the autocrine TGF $\beta 1$ signalling, which is responsible for sustaining or amplifying the fibrotic responses in the pathogenesis of SSc [7]. 
Former sequence analysis of the human XYLT1 promoter region revealed several downstream transcription factors of the EGR-, SP1- or KLF-family to regulate XYLT1 mRNA expression [28,29,43]. Giving the missing link between promoter analysis, identified transcription factors and upstream cellular signalling mediating XYLT1 expression in response to TGF $\beta$ cytokine stimulation of ALK receptors, we found a novel signalling axis involving MAPK and Smad proteins in activin A-mediated XT-I regulation in primary NHDF cells. Earlier studies by Takagi et al. on NHDF and SSc patients derived fibroblasts showed an activin A-induced phosphorylation of Smad2/3 after $4 \mathrm{~h}$ cytokine treatment, which could be reversed by ALK4 inhibition [10]. In agreement with the previous findings, we show here that the activin A-mediated effects on XYLT1 mRNA and XT-I expression increases were ALK4-dependent in NHDF.

The ALK4-activin A-induced signal transduction can be promoted via canonical Smad or non-canonical, non-Smad pathways in human fibroblasts [10,16]. Regarding the role of non-canonical pathways, we found here for the first time that MAPK JNK, p38 and ERK are involved in ALK4-activin A-mediated XYLT1 expression regulation in NHDF. The involvement of p38 MAPK in the TGF $\beta$ pathway promoted XT-I mRNA and the activity increase were observed in cultured human cardiac fibroblasts stimulated with TGF $\beta 1$ and corresponds with an elevated amount of digested GAG content in cardiac tissues from patients with myocardial fibrosis [27]. Additionally, in a recent study JNK and p38 were shown to be involved in growth factor thrombin or IL-1 $\beta$-induced XYLT1 mRNA expression increase in vascular smooth-muscle cells or primary chondrocyte cells $[43,49]$.

While we demonstrated the contribution of the three MAPKs JNK, p38 and ERK in activin A-driven XYLT1 expression increase in NHDF by the usage of small-molecule inhibitors, we were unable to detect a more pronounced decrease of activin A-mediated effects by simultaneous blocking of MAPK JNK and p38 compared to single p38, JNK or ERK inhibition. These data indicate reciprocal activation loops in the MAPK network itself or potential mechanisms of MAPK crosstalk and regulation by other signalling pathways [50,51]. The used SP600125 inhibitor concentration of $25 \mu \mathrm{mol} / \mathrm{L}$ in this study was previously shown not to block ERK1/2 and p38 phosphorylation [35], whereas blockade of p38 by SB203580 using an inhibitor concentration of $10 \mu \mathrm{mol} / \mathrm{L}$ resulted in a formerly identified increase on both ERK1/2 and JNK phosphorylation in primary hepatocytes and primary portal myofibroblasts [50]. Because of this cross-activation of MAPK signalling by MAPK inhibitors itself [35,50,52,53], it cannot be excluded that blocking of single MAPK JNK, p38 or ERK or simultaneous blocking of JNK and p38 MAPK pathways by the used small-molecule inhibitors in this study leads to a simultaneous activation of the other MAPKs driven by activin A. Therefore, no conclusion can be made on the basis of the observed relative extent of individual or combinatory MAPK inhibitions on the activin A-induced XYLT1 mRNA expression increase.

Regarding the role of the canonical Smad signalling pathway, we suggest a Smad2-dependency of activin A-regulated XYLT1 transcription, while Smad3 could be shown to be dispensable for XYLT1 expression increase. Interestingly, we observed a slight inhibitory action of Smad3 with regard to the basal XYLT1 expression of NHDF. In accordance with these findings, the full length XYLT1 promoter does not provide a Smad binding element, except our group did identify the XYLT1 promoter SNV with allele frequencies of $38 \%$, detected in healthy blood donors, in which the base exchange c.-1088C $>\mathrm{A}$ results in a Smad3 transcription factor binding site that significantly reduced basal promoter activity by $48.1 \% \pm 3 \%$ compared to promoter constructs without the mutation [54]. It might therefore be plausible that the slight increase in basal XYLT1 expression observed in the Smad3-inhibited fibroblast cells of this study were due to this SNV. As former studies did not reveal any differences in serum enzyme activity in these blood donors harbouring the appropriate XYLT1 promoter SNV c.-1088C >A [29], the corresponding XYLT1 promoter SNV in this cells was therefore not considered further by sequencing for dividing into subgroups.

Additionally, the cell-type specific activation of individual MAPK JNK, p38 and ERK has been demonstrated to phosphorylate the regulatory linker region of Smad2 protein [13,49]. As Smad signalling is critical to fibroblast activation and fibrosis induced by activin A [49,55], inhibition of 
Smad2 signalling by usage of MAPK inhibitors might have contributed to the suppressed XYLT1 expression increase in activin A-stimulated cells shown in this study. Several studies using human VSMC have demonstrated the dependency of PG synthesis on the phosphorylation of the Smad2 linker region. These studies especially highlighted Smad2 linker residue Thr220 regarding the transcriptional regulation of XT-I that can undergo phosphorylation by two of the three MAPKs p38, ERK and JNK after TGF $\beta$ or thrombin stimulation of VSMC $[49,56]$. As our results show that activin A-mediated XYLT1 expression increase is dependent on SMAD2 expression and involves the activity of MAPK JNK, p38 and ERK, and thus possibly JNK, p38 and ERK initiate non-canonical phosphorylation of the Smad2 linker region, which could have an inducible effect on XYLT1 mRNA expression in NHDF.

Deregulation of Smad7 expression has been associated with various human diseases, such as tissue fibrosis or systemic sclerosis [57]. Given the Smad3-dispensibilty of XYLT1 expression regulation, we indirectly assumed the positive regulatory impact of increased Smad2 availability on XYLT1 mRNA expression increase by depletion of Smad inhibitor Smad7. We could show that decreased SMAD7 expression, mimicking SSc fibroblasts, increased activin A-driven XYLT1 expression up-regulation but did not affect basal XYLT1 expression. These data confirm the reliability of the used cell culture model and the role of XT-I as a marker for myofibroblast differentiation in fibrosis, as demonstrated in previous studies [26].

Former studies using activin A and a human neuroblastoma cell line demonstrated that the expression of some TGF $\beta$ superfamily target genes induced by ALK4-activin A did not require promoter bindings of SMAD2/3 [10]. By taking into consideration that of the XYLT1 promoter does not provide the according Smad binding site [29], but Smad2 linker phosphorylation was shown to enhance the nuclear localisation of Smad2 proteins [55], we presume that a potential activin A-ALK4 signalling pathway in NHDF is transduced by the MAPK JNK, p38 and ERK pathways and potential phosphorylation of the Smad2 linker region, promoting the nuclear entrance and favoured binding of Smad 2 to the former identified transcription factors AP1 and SP1/3, known to increase XYLT1 expression [28,29,58-61].

Interestingly, we found differential dependency of XYLT isoform expression on Smad3 and ERK. In comparison to basal XYLT1 expression, which is increased by ERK and supressed by Smad3, basal XYLT2 expression is increased by Smad3 and ERK in NHDF. This observation can be explained by considering the results of this current work and the previous XYLT1 and XYLT2 promoter analysis performed in our group. In contrast to the promoter region of XYLT1, the XYLT2 promoter does not exhibit a binding site for the AP1 transcription factor, which plays a considerable role in the regulation of XYLT1 gene by JNK and p38 [43], explaining why basal XYLT2 expression was not influenced by the usage of $\mathrm{p} 38$ and JNK inhibitors in this study. While the XYLT1 promoter exhibits numerous transcription-binding sites for EGR1, which was previously shown to response to non-canonical, Smad3-independent TGF $\beta$ pathway MEK/ERK in SScF [60], the main transcription factors substantially involved in XYLT2 promoter regulation are SP1/3 [29,30,62]. These findings are consistent with previously published data demonstrating dose-dependent inhibition of SMAD3 promoter activity by ERK inhibitor UO126 that correlates with the inhibition of SP1/SP3 function by the same inhibitor [63]. Therefore, it is likely that apparent SMAD3 expression due to ERK inhibition has led to diminish basal XYLT2 expression. In accordance to Smad3 expression, which was shown to be down-regulated in former published data after TGF $\beta 1$ treatment [64,65], XYLT2 expression decreases in a SMAD3-dependent manner.

The knockdown of Smad2 in NHDF resulted in higher basal XYLT2 expression, suggesting that Smad2 acts as a transcriptional suppressor. Additionally, the inhibition of SMAD7 expression mimics the effect of Smad2 silencing on basal XYLT2 expression in NHDF. It is described that active Smad proteins interfere with transcription factor complexes mediating repression of target gene expression [66]. Therefore, Smad2 and Smad3 binding to SP1 and their relative distribution to XYLT2 gene expression regulation in NHDF require further clarification. With the knowledge that basal XYLT2 expression relies on Smad3, the depletion of Smad2 in this study could have raised the endogenous ratio of Smad3 in comparison to Smad2. This could have led to the observed XYLT2 expression increase in 
Smad2-depleted cells. The impact of siRNA-mediated knockdown of single Smad proteins on the endogenous Smad2/3 ratio and their respective complex formation has been shown in previous studies to change the outcome of target gene expression [67]. Future studies will be necessary to evaluate this reciprocal basal XYLT2 expression regulation by Smads 2, 3 and 7 in NHDF.

\section{Conclusions}

Taken together, our data identify, for the first time, XT-I as a target of activin A-mediated pro-fibrotic effects in NHDF. XYLT2 isoform expression was unchanged by activin A. We demonstrated the critical role for Smad2 and MAPK JNK, p38 and ERK in the underlying signalling pathways of increased XYLT1 expression by activin A. Furthermore, we detected a differential regulation of basal XYLT1 and $X Y L T 2$ isoform transcription by MAPK and Smad proteins. This knowledge develops an enhanced understanding for their distinct expression pattern in tissues or under pathological conditions, and might be useful for isoform-specific activation or repression strategies of clinical relevance.

Supplementary Materials: The following are available online at http://www.mdpi.com/2218-273X/10/4/609/s1, Figure S1: Various Cytokine and growth factor treatments of NHDF. Figure S2: Interleukin treatments of NHDF. Figure S3: Inhibition of basal XYLT2 mRNA expression by pharmacological inhibitors to MAPK JNK, p38 and ERK. Figure S4: siRNA-mediated Smads 2, 3 and 7 knockdowns.

Author Contributions: Conceptualization, T.-D.L., D.H., C.K. and I.F.; data curation, T.-D.L. and I.F; formal analysis, T.-D.L.; funding acquisition, I.F.; investigation, T.-D.L. and R.P.; methodology, R.P., V.S. and J.K.; project administration, D.H. and I.F.; resources, B.F.; supervision, C.K.; validation, B.F., V.S. and J.K.; visualization, T.-D.L.; writing—original draft, T.-D.L.; writing—review and editing, R.P., B.F., V.S., D.H., J.K., C.K. and I.F. All authors have read and agreed to the published version of the manuscript.

Funding: This research was funded by the German Research Foundation (Deutsche Forschungsgemeinschaft, DFG; FA 1381/1-1).

Acknowledgments: We thank Philip Saunders for linguistic advice and Christoph Lichtenberg for technical assistance.

Conflicts of Interest: The authors declare no conflict of interest.

\section{References}

1. Pasparakis, M.; Haase, I.; Nestle, F.O. Mechanisms regulating skin immunity and inflammation. Nat. Rev. Immunol. 2014, 14, 289-301. [CrossRef] [PubMed]

2. Zhao, X.; Psarianos, P.; Ghoraie, L.S.; Yip, K.; Goldstein, D.; Gilbert, R.; Witterick, I.; Pang, H.; Hussain, A.; Lee, J.H.; et al. Metabolic regulation of dermal fibroblasts contributes to skin extracellular matrix homeostasis and fibrosis. Nat. Metab. 2019, 1, 147-157. [CrossRef]

3. Do, N.N.; Eming, S.A. Skin fibrosis: Models and mechanisms. Curr. Res. Transl. Med. 2016, 64, $185-193$. [CrossRef]

4. Yazdani, S.; Bansal, R.; Prakash, J. Drug targeting to myofibroblasts: Implications for fibrosis and cancer. Adv. Drug Deliv. Rev. 2017, 121, 101-116. [CrossRef]

5. Werner, S.; Smola, H. Paracrine regulation of keratinocyte proliferation and differentiation. Trends in Cell Biology 2001, 11, 143-146. [CrossRef]

6. Borthwick, L.A.; Wynn, T.A.; Fisher, A.J. Cytokine mediated tissue fibrosis. Biochim. Biophys. Acta Mol. Basis Dis. 2013, 1832, 1049-1060. [CrossRef]

7. Ihn, H. Autocrine TGF- $\beta$ signaling in the pathogenesis of systemic sclerosis. J. Dermatol. Sci. 2008, 49, 103-113. [CrossRef]

8. Wang, X.; Fischer, G.; Hyvönen, M. Structure and activation of pro-activin A. Nat. Commun. $2016,7$. [CrossRef]

9. Annes, J.P. Making sense of latent TGFbeta activation. J. Cell Sci. 2003, 116, 217-224. [CrossRef]

10. Takagi, K.; Kawaguchi, Y.; Kawamoto, M.; Ota, Y.; Tochimoto, A.; Gono, T.; Katsumata, Y.; Takagi, M.; Hara, M.; Yamanaka, H. Activation of the Activin A-ALK-Smad pathway in systemic sclerosis. J. Autoimmun. 2011, 36, 181-188. [CrossRef]

11. Jones, K.L.; De Kretser, D.M.; Patella, S.; Phillips, D.J. Activin A and follistatin in systemic inflammation. Mol. Cell. Endocrinol. 2004, 225, 119-125. [CrossRef] [PubMed] 
12. Antsiferova, M.; Werner, S. The bright and the dark sides of activin in wound healing and cancer. J. Cell Sci. 2012, 125, 3929-3937. [CrossRef] [PubMed]

13. Tsuchida, K.; Nakatani, M.; Hitachi, K.; Uezumi, A.; Sunada, Y.; Ageta, H.; Inokuchi, K. Activin signaling as an emerging target for therapeutic interventions. Cell Commun. Signal. 2009, 7, 1-11. [CrossRef] [PubMed]

14. Fibroblasts, L.; Ohga, E.; Matsuse, T.; Teramoto, S.; Katayama, H.; Nagase, T.; Fukuchi, Y.; Ouchi, Y. Effects of Activin A on Proliferation and Differentiation Activin A is a dimeric protein that was isolated from ovarian fluid as a stimulator of follicle- stimulating hormone (FSH). Biochem. Biophys. Res. Commun. 1996, 228, 391-396.

15. Yamashita, S.; Maeshima, A.; Kojima, I.; Nojima, Y. Activin A Is a Potent Activator of Renal Interstitial Fibroblasts. J. Am. Soc. Nephrol. 2004, 15, 91-101. [CrossRef]

16. Hu, J.; Wang, X.; Wei, S.M.; Tang, Y.H.; Zhou, Q.; Huang, C.X. Activin A stimulates the proliferation and differentiation of cardiac fibroblasts via the ERK1/2 and p38-MAPK pathways. Eur. J. Pharmacol. 2016, 789, 319-327. [CrossRef]

17. Bao, Y.L.; Tsuchida, K.; Liu, B.; Kurisaki, A.; Matsuzaki, T.; Sugino, H. Synergistic activity of activin A and basic fibroblast growth factor on tyrosine hydroxylase expression through Smad3 and ERK1/ERK2 MAPK signaling pathways. J. Endocrinol. 2005, 184, 493-504. [CrossRef]

18. Susarla, B.T.S.S.; Laing, E.D.; Yu, P.; Katagiri, Y.; Geller, H.M.; Symes, A.J. Smad proteins differentially regulate transforming growth factor- $\beta$-mediated induction of chondroitin sulfate proteoglycans. J. Neurochem. 2011, 119, 868-878. [CrossRef]

19. Bhattacharyya, S.; Chen, S.J.; Wu, M.; Warner-Blankenship, M.; Ning, H.; Lakos, G.; Mori, Y.; Chang, E.; Nihijima, C.; Takehara, K.; et al. Smad-independent transforming growth factor- $\beta$ regulation of early growth response-1 and sustained expression in fibrosis: Implications for scleroderma. Am. J. Pathol. 2008, 173, 1085-1099. [CrossRef]

20. Li, S.; Shimono, C.; Norioka, N.; Nakano, I.; Okubo, T.; Yagi, Y.; Hayashi, M.; Sato, Y.; Fujisaki, H.; Hattori, S.; et al. Activin A binds to perlecan through its pro-region that has heparin/heparan sulfate binding activity. J. Biol. Chem. 2010, 285, 36645-36655. [CrossRef]

21. Kleesiek, K.; Reinards, R.; Okusi, J.; Wolf, B.; Greiling, H. UDP-D-Xylose: Proteoglycan Core Protein $\beta$-D-Xylosyltransferase: A New Marker of Cartilage Destruction in Chronic Joint Diseases. Clin. Chem. Lab. Med. 1987, 25. [CrossRef] [PubMed]

22. Pönighaus, C.; Speirs, H.J.L.; Morris, B.J.; Kuhn, J.; Kleesiek, K.; Götting, C. Xylosyltransferase gene variants and their role in essential hypertension. Am. J. Hypertens. 2009, 22, 432-436. [CrossRef] [PubMed]

23. Götting, C.; Kuhn, J.; Zahn, R.; Brinkmann, T.; Kleesiek, K. Molecular Cloning and Expression of Human UDP-d-Xylose:Proteoglycan Core Protein $\beta$-d-Xylosyltransferase and its First Isoform XT-II. J. Mol. Biol. 2000, 304, 517-528. [CrossRef] [PubMed]

24. Pönighaus, C.; Kuhn, J.; Kleesiek, K.; Götting, C. Involvement of a cysteine protease in the secretion process of human xylosyltransferase I. Glycoconj. J. 2010, 27, 359-366. [CrossRef] [PubMed]

25. Götting, C.; Sollberg, S.; Kuhn, J.; Weilke, C.; Huerkamp, C.; Brinkmann, T.; Krieg, T.; Kleesick, K.; Kleesiek, K.; Sollberg, S.; et al. Serum xylosyltransferase: A new biochemical marker of the sclerotic process in systemic sclerosis. J. Investig. Dermatol. 1999, 112, 919-924. [CrossRef]

26. Faust, I.; Roch, C.; Kuhn, J.; Prante, C.; Knabbe, C.; Hendig, D. Human xylosyltransferase-I - A new marker for myofibroblast differentiation in skin fibrosis. Biochem. Biophys. Res. Commun. 2013, 436, 449-454. [CrossRef]

27. Prante, C.; Milting, H.; Kassner, A.; Farr, M.; Ambrosius, M.; Schon, S.; Seidler, D.G.; Banayosy, A.E.; Korfer, R.; Kuhn, J.; et al. Transforming Growth Factor beta1-regulated Xylosyltransferase I Activity in Human Cardiac Fibroblasts and Its Impact for Myocardial Remodeling. J. Biol. Chem. 2007, 282, 26441-26449. [CrossRef]

28. Müller, B.; Prante, C.; Kleesiek, K.; Götting, C.; Muller, B.; Prante, C.; Kleesiek, K.; Gotting, C. Identification and Characterization of the Human Xylosyltransferase I Gene Promoter Region. J. Biol. Chem. 2009, 284, 30775-30782. [CrossRef]

29. Faust, I.; Böker, K.O.; Lichtenberg, C.; Kuhn, J.; Knabbe, C.; Hendig, D. First description of the complete human xylosyltransferase-I promoter region. BMC Genet. 2014, 15, 1. [CrossRef]

30. Müller, B.; Prante, C.; Knabbe, C.; Kleesiek, K.; Götting, C. First identification and functional analysis of the human xylosyltransferase II promoter. Glycoconj. J. 2013, 30, 237-245. [CrossRef]

31. Pfaffl, M.W. A new mathematical model for relative quantification in real-time RT-PCR. Nucl. Acids Res. 2001, 29, e45. [CrossRef] [PubMed] 
32. Götting, C.; Kuhn, J.; Tinneberg, H.-R.; Brinkmann, T.; Kleesiek, K. High xylosyltransferase activities in human follicular fluid and cultured granulosa-lutein cells. Mol. Hum. Reprod. 2002, 8, 1079-1086. [CrossRef] [PubMed]

33. Mori, Y.; Ishida, W.; Bhattacharyya, S.; Li, Y.; Platanias, L.C.; Varga, J. Selective inhibition of activin receptor-like kinase 5 signaling blocks profibrotic transforming growth factor $\beta$ responses in skin fibroblasts. Arthr. Rheum. 2004, 50, 4008-4021. [CrossRef] [PubMed]

34. Inman, G.J.; Nicolás, F.J.; Callahan, J.F.; Harling, J.D.; Gaster, L.M.; Reith, A.D.; Laping, N.J.; Hill, C.S. SB-431542 is a potent and specific inhibitor of transforming growth factor- $\beta$ superfamily type I activin receptor-like kinase (ALK) receptors ALK4, ALK5, and ALK7. Mol. Pharmacol. 2002, 62, 65-74. [CrossRef]

35. Bennett, B.L.; Sasaki, D.T.; Murray, B.W.; Leary, E.C.O.; Sakata, S.T.; Xu, W.; Leisten, J.C.; Motiwala, A.; Pierce, S.; Satoh, Y.; et al. SP600125, an Anthrapyrazolone Inhibitor of Jun N-Terminal Kinase. Proc. Natl. Acad. Sci. USA 2001, 98, 13681-13686. [CrossRef]

36. Henklova, P.; Vrzal, R.; Papouskova, B.; Bednar, P.; Jancova, P.; Anzenbacherova, E.; Ulrichova, J.; Maurel, P.; Pavek, P.; Dvorak, Z. SB203580, a pharmacological inhibitor of p38 MAP kinase transduction pathway activates ERK and JNK MAP kinases in primary cultures of human hepatocytes. Eur. J. Pharmacol. 2008, 593, 16-23. [CrossRef]

37. Dumas, J. Protein kinase inhibitors: Emerging pharmacophores 1997 - 2000. Expert Opin. Ther. Pat. 2001, 11, 405-429. [CrossRef]

38. Jinnin, M.; Ihn, H.; Tamaki, K. Characterization of SIS3, a novel specific inhibitor of Smad3, and its effect on transforming growth factor- $\beta 1$-induced extracellular matrix expression. Mol. Pharmacol. 2006, 69, 597-607. [CrossRef]

39. Kuhn, J.; Gressner, O.A.; Götting, C.; Gressner, A.M.; Kleesiek, K. Increased serum xylosyltransferase activity in patients with liver fibrosis. Clin. Chim. Acta 2009, 409, 123-126. [CrossRef] [PubMed]

40. Kitabatake, M.; Ishikawa, H.; Maeda, H. Immunohistochemical demonstration of proteoglycans in the skin of patients with systemic sclerosis. Br. J. Dermatol. 1983, 108, 257-262. [CrossRef] [PubMed]

41. Kuroda, K.; Shinkai, H. Decorin and glycosaminoglycan synthesis in skin fibroblasts from patients with systemic sclerosis. Arch. Dermatol. Res. 1997, 289, 481-485. [CrossRef] [PubMed]

42. Walton, K.L.; Johnson, K.E.; Harrison, C.A. Targeting TGF- $\beta$ Mediated SMAD Signaling for the Prevention of Fibrosis. Front. Pharmacol. 2017, 8. [CrossRef] [PubMed]

43. Khair, M.; Bourhim, M.; Barré, L.; Li, D.; Netter, P.; Magdalou, J.; Fournel-Gigleux, S.; Ouzzine, M. Regulation of Xylosyltransferase I Gene Expression by Interleukin $1 \beta$ in Human Primary Chondrocyte Cells: MECHANISM AND IMPACT ON PROTEOGLYCAN SYNTHESIS. J. Biol. Chem. 2013, 288, 1774-1784. [CrossRef] [PubMed]

44. Ye, W.; Zhou, J.; Markova, D.Z.; Tian, Y.; Li, J.; Anderson, D.G.; Shapiro, I.M.; Risbud, M.V. Xylosyltransferase-1 expression is refractory to inhibition by the inflammatory cytokines tumor necrosis factor $\alpha$ and IL- $1 \beta$ in nucleus pulposus cells: Novel regulation by AP-1, Sp1, and Sp3. Am. J. Pathol. 2014, 185, 485-495. [CrossRef]

45. Faust, I.; Donhauser, E.; Fischer, B.; Ibold, B.; Kuhn, J.; Knabbe, C.; Hendig, D. Characterization of dermal myofibroblast differentiation in pseudoxanthoma elasticum. Exp. Cell Res. 2017, 360, 153-162. [CrossRef]

46. Fischer, B.; Ly, T.; Hendig, D.; Kuhn, J.; Pécheur, E.; Reungoat, E.; Knabbe, C.; Faust, I. Biochem. Biophys. Res. Commun. First description of a compensatory xylosyltransferase I induction observed after an anti fi brotic UDP-treatment of normal human dermal fi broblasts. Biochem. Biophys. Res. Commun. 2019, 512, 7-13. [CrossRef]

47. Riedel, L.; Fischer, B.; Ly, T.-D.; Hendig, D.; Kuhn, J.; Knabbe, C.; Faust, I. microRNA-29b mediates fibrotic induction of human xylosyltransferase-I in human dermal fibroblasts via the Sp1 pathway. Sci. Rep. 2018, 8, 17779. [CrossRef]

48. Garrett, S.M.; Baker Frost, D.; Feghali-Bostwick, C. The Mighty Fibroblast and Its Utility in Scleroderma Research. J. Scleroderma Relat. Disord. 2017, 2, 100-107. [CrossRef]

49. Kamato, D.; Burch, M.; Zhou, Y.; Mohamed, R.; Stow, J.L.; Osman, N.; Zheng, W.; Little, P.J. Individual Smad2 linker region phosphorylation sites determine the expression of proteoglycan and glycosaminoglycan synthesizing genes. Cell. Signal. 2019, 53, 365-373. [CrossRef]

50. Meurer, S.K.; Weiskirchen, R. Usage of Mitogen-activated protein kinase small molecule inhibitors: More than just inhibition! Front. Pharmacol. 2018, 9, 9-11. [CrossRef] 
51. Dolivo, D.M.; Larson, S.A.; Dominko, T. Crosstalk between mitogen-activated protein kinase inhibitors and transforming growth factor- $\beta$ signaling results in variable activation of human dermal fibroblasts. Int. J. Mol. Med. 2019, 43, 325-335. [CrossRef] [PubMed]

52. Kempf, H.; Lecina, M.; Ting, S.; Zweigerdt, R.; Oh, S. Distinct regulation of mitogen-activated protein kinase activities is coupled with enhanced cardiac differentiation of human embryonic stem cells. Stem Cell Res. 2011, 7, 198-209. [CrossRef] [PubMed]

53. Hotokezaka, H.; Sakai, E.; Kanaoka, K.; Saito, K.; Matsuo, K.; Kitaura, H.; Yoshida, N.; Nakayama, K. U0126 and PD98059, Specific Inhibitors of MEK, Accelerate Differentiation of RAW264.7 Cells into Osteoclast-like Cells. J. Biol. Chem. 2002, 277, 47366-47372. [CrossRef]

54. Suzuki, K.; Kobayashi, T.; Funatsu, O.; Morita, A.; Ikekita, M. Biochem. Biophys. Res. Commun. Activin A induces neuronal differentiation and survival via ALK4 in a SMAD-independent manner in a subpopulation of human neuroblastomas. Biochem. Biophys. Res. Commun. 2010, 394, 639-645. [CrossRef] [PubMed]

55. Rostam, M.A.; Shajimoon, A.; Kamato, D.; Mitra, P.; Piva, T.J.; Getachew, R.; Cao, Y.; Zheng, W.; Osman, N.; Little, P.J. Flavopiridol Inhibits TGF- $\beta$-Stimulated Biglycan Synthesis by Blocking Linker Region Phosphorylation and Nuclear Translocation of Smad2. J. Pharmacol. Exp. Ther. 2018, 365, 156-164. [CrossRef] [PubMed]

56. Rostam, M.A.; Kamato, D.; Piva, T.J.; Zheng, W.; Little, P.J.; Osman, N. The role of specific Smad linker region phosphorylation in TGF- $\beta$ mediated expression of glycosaminoglycan synthesizing enzymes in vascular smooth muscle. Cell. Signal. 2016, 28, 956-966. [CrossRef]

57. Mori, Y.; Chen, S.J.; Varga, J. Expression and regulation of intracellular SMAD signaling in scleroderma skin fibroblasts. Arthr. Rheum. 2003, 48, 1964-1978. [CrossRef]

58. Venkatesan, N.; Barré, L.; Bourhim, M.; Magdalou, J.; Mainard, D.; Netter, P.; Fournel-Gigleux, S.; Ouzzine, M. Xylosyltransferase-I Regulates Glycosaminoglycan Synthesis during the Pathogenic Process of Human Osteoarthritis. PLoS ONE 2012, 7, e34020. [CrossRef]

59. Ihn, H.; Yamane, K.; Asano, Y.; Jinnin, M.; Tamaki, K. Constitutively phosphorylated Smad3 interacts with Sp1 and p300 in scleroderma fibroblasts. Rheumatology 2006, 45, 157-165. [CrossRef]

60. Bhattacharyya, S.; Sargent, J.L.; Du, P.; Lin, S.; Tourtellotte, W.G.; Takehara, K.; Whitfield, M.L.; Varga, J. Egr-1 induces a profibrotic injury/repair gene program associated with systemic sclerosis. PLoS ONE 2011, 6, 1-7. [CrossRef]

61. Piera-velazquez, S.; Makul, A.; Jimenez, S.A. Increased Expression of NAPDH Oxidase 4 (NOX4) in Systemic Sclerosis Dermal Fibroblasts: Regulation by Transforming Growth Factor $\beta$. Arthr. Rheumatol. 2016, 67, 2749-2758.

62. Tan, N.Y.; Khachigian, L.M. Sp1 Phosphorylation and Its Regulation of Gene Transcription. Mol. Cell. Biol. 2009, 29, 2483-2488. [CrossRef] [PubMed]

63. Ross, K.R.; Corey, D.A.; Dunn, J.M.; Kelley, T.J. SMAD3 expression is regulated by mitogen-activated protein kinase kinase-1 in epithelial and smooth muscle cells. Cellular Signalling 2007, 19, 923-931. [CrossRef]

64. Poncelet, A.-C.; De Caestecker, M.P.; Schnaper, H.W. The transforming growth factor- $\beta$ bgr/SMAD signaling pathway is present and functional in human mesangial cells. Kidney Int. 1999, 56, 1354-1365. [CrossRef] [PubMed]

65. Baugé, C.; Cauvard, O.; Leclercq, S.; Galéra, P.; Boumédiene, K. Modulation of transforming growth factor beta signalling pathway genes by transforming growth factor beta in human osteoarthritic chondrocytes: Involvement of Sp1 in both early and late response cells to transforming growth factor beta. Arthr. Res. Ther. 2011, 13, R23. [CrossRef]

66. Shi, Y.; Massagué, J. Mechanisms of TGF- $\beta$ signaling from cell membrane to the nucleus. Cell 2003, 113, 685-700. [CrossRef]

67. Ungefroren, H.; Groth, S.; Sebens, S.; Lehnert, H.; Gieseler, F.; Fändrich, F. Differential roles of Smad2 and Smad 3 in the regulation of TGF- $\beta 1$-mediated growth inhibition and cell migration in pancreatic ductal adenocarcinoma cells: Control by Rac1. Mol. Cancer 2011, 10, 67. [CrossRef] [PubMed]

(C) 2020 by the authors. Licensee MDPI, Basel, Switzerland. This article is an open access article distributed under the terms and conditions of the Creative Commons Attribution (CC BY) license (http://creativecommons.org/licenses/by/4.0/). 